\title{
MUCOADHESIVE BUCCAL FILMS: A NOVEL APPROACH FOR THE DELIVERY OF ANTI-HYPERTENSIVE DRUGS
}

\author{
ADESH YELAVE*, GEETA BHAGWAT \\ Department of Pharmaceutics, H.K. College of Pharmacy, Oshiwara, Mumbai, India. Email: adeshyelave.ay05@gmail.com
}

Received: 28 December 2020, Revised and Accepted: 13 February 2021

\section{ABSTRACT}

The buccal drug delivery system is a prominent route of administration for drug delivery through the buccal mucosa. It is rich in blood supply with more surface area for rapid absorption as well as provides direct entry of drugs from the site of application into the systemic circulation through the jugular vein. Buccal drug delivery systems consist of various approaches such as lozenges, wafers, gels, microparticles, patches or films from which mucoadhesive buccal film is an attractive dosage form in terms of flexibility and high systemic bioavailability. Since most of the antihypertensive drugs show first-pass metabolism which leads to less oral bioavailability generally up to 20-50\%. Thus, incorporation of antihypertensive drugs in mucoadhesive buccal films using mucoadhesive polymers can provide higher systemic bioavailability. The films can be formulated using various techniques such as solvent casting method and hot extrusion melt method. These films can be evaluated based on various characteristics to determine their efficacy and performance such as tensile strength, mucoadhesion residence time, and kinetic release data analysis. They have various advantages over conventional solid oral dosage forms, hence are preferable for the preparation of antihypertensive drug-loaded buccal films. Mucoadhesive buccal films of antihypertensive drugs can also provide controlled drug delivery with enhanced bioavailability.

Keywords: Jugular vein, Bioavailability, Wafers, Mucoadhesive polymers.

(C) 2021 The Authors. Published by Innovare Academic Sciences Pvt Ltd. This is an open access article under the CC BY license (http://creativecommons.org/ licenses/by/4.0/) DOI: http://dx.doi.org/10.22159/ajpcr.2021v14i4.40654. Journal homepage: https://innovareacademics.in/journals/index.php/ajpcr

\section{INTRODUCTION}

The buccal drug delivery system is the drug delivery system that emphasizes the drug administration through the mucosal membrane lining of the buccal cavity [1]. It acts as an attractive route of administration for the systemic delivery of drugs because of the rich vascularization of the buccal mucosa while also giving direct access to the drug through the jugular vein into the systemic circulation [2]. There are various approaches for the development of buccal drug delivery systems from which the mucoadhesive buccal films are more prominent and convenient for drug delivery. Buccal films are the dosage forms that involve hydration of water-soluble polymers to adhere and dissolve when applied between gums and cheeks, which can result in systemic drug delivery [2]. Hypertension is a condition in which blood pressure on the arteries is drastically elevated because of various factors (physiological and pathophysiological) [3]. Blood pressure is the force on the arteries when blood flows through blood vessels. Hypertension can be classified as primary hypertension (has an unknown cause) and secondary hypertension (has known cause) [3]. Majority of patients suffer from primary hypertension. Secondary hypertension is a result of various conditions that may affect vital organs such as kidney, heart, or endocrine glands. Blood pressure is measured as systolic blood pressure to diastolic blood pressure. The usual blood pressure of normal adults should be $120 / 80 \mathrm{~mm}$ of $\mathrm{Hg}$ while the patient suffering from hypertension shows blood pressure more than 140/90 $\mathrm{mm}$ of $\mathrm{Hg}$ [4]. The drugs used for the treatment of hypertension are termed as antihypertensive drugs [5]. Antihypertensive drugs have various mechanisms to lower high blood pressure. Antihypertensive drugs are also used in the treatment of cardiovascular disorder such as myocardial infarction, cardiac arrhythmias, and cardiac strokes; kidney diseases such as chronic nephropathy [6]. Unfortunately administration of antihypertensive drugs through oral route shows less bioavailability up to $30-40 \%$ [6]. The major factor responsible for the delayed bioavailability of antihypertensive drugs is hepatic first-pass metabolism [7]. The inclusion of drug in the buccal films, avoids the hepatic first-pass metabolism leading to high systemic bioavailability [7]. Thus, buccal films can be a prominent alternative for the administration of antihypertensive drugs than other oral dosage forms.

\section{PATHOPHYSIOLOGY OF HYPERTENSION}

Physiologically, hypertension is a condition in which the blood pressure is elevated above the normal value, that is, $140 / 90 \mathrm{~mm}$ of $\mathrm{Hg}$. In clinical terms, blood pressure can be referred to as the pressure in arteries produced by left ventricle after ventricular contraction and the pressure in arteries by remaining blood in ventricles during ventricular relaxation [8]. The blood pressure is measured as the systolic blood pressure to diastolic blood pressure. Systolic blood pressure is the force of blood pressure on arterial walls just after ventricular contraction whereas diastolic blood pressure is the force exerted by the blood remaining in the arteries during ventricular relaxation [9]. The normal blood pressure reading is 140/90 $\mathrm{mm} \mathrm{Hg}$. Hypertension can be classified as essential (primary or idiopathic) hypertension and secondary hypertension [9]. Essential hypertension is a very common type of hypertension with an unknown cause which accounts for $95 \%$ of all cases of hypertension [10]. While secondary hypertension has known cause which may be a result of any physiological or pathophysiological factors, accounts for $5 \%$ of all cases of hypertension [10]. There are various factors responsible for elevating blood pressure which results in hypertensive conditions. The major factors are as follows,

\section{Cardiac output and peripheral vascular resistance}

Normal blood pressure can be maintained through a balance between cardiac output and peripheral vascular resistance [9]. Patients with primary hypertension show normal cardiac output but increased peripheral vascular resistance. Peripheral vascular resistance is determined by small arterioles present on the walls of smooth muscles. Hence, it can be concluded that the contraction of smooth muscles due to a rise in intracellular calcium can lead to an increase in peripheral resistance $[5,9]$. Thus, it may explain vasodilator action of calcium channel blockers in the hypertensive state [6]. While prolonged contractions of smooth muscle can lead to structural damage to arteriolar vessels possibly triggered by angiotensin, which may result 
in an irreversible elevation in peripheral resistance. Clinically due to hypersecretion of epinephrine and norepinephrine (may be caused by a tumor in adrenal medulla) shows positive inotropic and positive chronotropic effects, leading to increased total peripheral resistance [8].

\section{Overactivation of resin-angiotensin-aldosterone (RAA) system}

RAA system helps in the homeostasis for maintaining blood pressure in the body by regulating the secretion of aldosterone [9]. Some physiological conditions such as dehydration, $\operatorname{sodium}\left(\mathrm{Na}^{+}\right)$deficiency, or hemorrhage, and blood volume gets decreased which eventually results into drop in normal blood pressure [9]. This drop in blood pressure triggers the juxtamedullary cells of the kidney to secrete renin in the blood resulting in increase in renin concentration in the blood. In liver, renin converts angiotensinogen (inactive) to angiotensin I. Further angiotensin I is converted into angiotensin II (active) by angiotensinconverting enzyme (ACE) in the lungs. Angiotensin II works in two ways to regulate blood pressure [11]. First, angiotensin II stimulates the contraction of smooth muscles of vascular arterioles which increases the blood pressure to a normal state. Second, angiotensin II triggers the adrenal cortex to release aldosterone (glucocorticoid which maintains the salt and water reabsorption). Aldosterone increases the reabsorption of $\mathrm{Na}^{+}$which, in turn, causes the reabsorption of water by osmosis [11]. This helps to maintain the blood volume by limiting the water loss through urine. Aldosterone also increases the secretion of $\mathrm{K}^{+} \& \mathrm{H}^{+}$ions into the urine which are then excreted [11]. Sometimes obstruction of renal blood flow or disorders that damages renal tissues may cause the kidney to secrete excessive amounts of renin into the blood. Thus resulting in an increasing amount of angiotensin II which leads to increased systemic vascular resistance by vasoconstriction of arterioles [8]. This may explain the function of angiotensin II receptor inhibitors in the treatment of hypertension [4]. Due to abnormalities in the adrenal cortex, the secretion of aldosterone is increased drastically which leads to excessive reabsorption of salts and water. Thereby the blood pressure is raised to an abnormal state. Thus, it can explain the function of aldosterone inhibitors in the treatment of hypertension [5].

\section{Endothelial dysfunction OR Endothelial injury}

The vascular endothelial layer has its unique role in the maintenance of blood pressure to the normal state [5]. They can produce the various potent locally acting vasoactive agents. It includes nitric acid (NO) (vasodilator) and peptide endothelin (vasoconstrictor). Hence, endothelial dysfunction or endothelial injury has to be considered while the treatment of hypertension [9]. Thus, modulation of the endothelial function should be considered as an essential factor for minimizing hypertension. Clinically, the use of nitroglycerides as vasodilators can be the primary treatment of hypertension by restoring the impaired production of nitric oxide thus enabling normal function again [9].

\section{Endocrine system}

In condition such as dehydration or decreased blood pressure, the baroreceptors in the brain get triggered. These stimuli allow the hypothalamus to produce an antidiuretic hormone ( $\mathrm{ADH})$ and it is released from the posterior region of the pitutory gland into the bloodstream [9]. ADH causes the vasoconstriction of arterioles and veins in the skin which elevates the blood pressure to a normal state, while ADH also promotes the reabsorption of water from renal tubules into the bloodstream to increase the blood volume by decreasing urine output. Abnormalities in the functioning in hypothalamus region may cause the overproduction of ADH which leads to excessive stimulation of ADH receptors in kidneys [8]. This may produce the hypertensive state due to overactivation of ADH receptors. Hence, the antidiuretic receptor antagonists can help in the treatment of hypertension $[6,11]$.

\section{BUCCAL FILMS}

Buccal films are the laminar structure that consists of a drug-polymer solution layer with other excipients, an impermeable backing layer, and a bioadhesive surface for attachment to the buccal mucosa [12]. There are two types of designs for the manufacturing of buccal films, that is, matrix type and reservoir type [13]. Matrix type buccal films involve the dispersion of drug into a matrix polymer solution which provides controlled drug release. While reservoir type buccal films consist of a space or cavity for a drug-polymer solution in which drug is dissolved, which is separated from bioadhesive [13]. An impermeable backing layer is used to control the direction of drug release and to avoid unnecessary multidirectional drug release as it prevents drug loss [14]. The buccal epithelium layer is the main barrier to the transport of drugs through the buccal mucosa [12]. Drug transport from buccal mucosa can be either paracellular or transcellular transport [13-15]. Paracellular transport (also called as intercellular transport) is defined as the transport of drugs through the junctions between mucosal epithelial cells [15]. While transcellular transport (also called intracellular transport) is defined as the transport of the drug across mucosal epithelium, which is the most common pathway for drug transport [15]. Highly lipophilic drugs and macromolecules permeate buccal mucosa through passive transcellular transport whereas lipophilic compounds and small hydrophobic molecules predominantly pass through paracellular transport [15]. The drug transport is also depended on the permeation enhancers used in buccal films. They have a different mechanism for the transport of drugs through mucosal cell lining [16].

\section{ADVANTAGES}

\section{High patient compliance}

The painless administration of dosage form which is considered as one of the major advantages of the buccal films [13]. The ease of application makes it patient friendly. Patients can control the period of administration or termination emergencies, without any special assistance. The parenteral route of administration is associated with pain; hence, buccal films can be more convenient for children and elderly patients [12,17-19]. It also does not need chewing and swallowing of the dosage form. Mostly elderly patients suffer from hypertension so sometimes it is not feasible to administer conventional solid oral dosage forms for such patients and hence buccal films can be preferred due to their ease of application [7].

\section{Increased systemic bioavailability}

The buccal mucosa is rich in vascular intervention for direct access of drug into systemic circulation through jugular vein as well as it provides a large mucosal surface for absorption [16]. This can provide enhanced systemic bioavailability for poorly absorbed drugs than conventional dosage forms. As most of the antihypertensive drugs possess less bioavailability given the fact of their high hepatic first-pass metabolism when administered through the oral route and hence to overcome this problem buccal films may be an attractive route for delivery of antihypertensive drugs [7,20-23].

\section{Rapid onset of action}

Buccal mucosa provides a rich blood supply for local drug absorption from the buccal cavity hence is advantageous $[1,12]$. Thus, it gives the rapid onset of action in a short period of time. Ideally, antihypertensive drugs should have a rapid onset of action but when it goes through the oral route, it takes time for absorption which leads to the slow onset of action [16]. This slow onset of action is not feasible in emergencies where the patient is unconscious. Therefore, buccal films can be a substitute dosage form for conventional one to provide antihypertensive drugs with rapid absorption through rapid transport of drugs through buccal mucosa into the systemic circulation [7].

\section{Protection from GI degradation}

Drugs that are liable for acid degradation in the stomach can be administered by buccal drug delivery system [24]. This route of administration can avoid drug loss by stomach acid degradation. It also reduces the GI side effects of antihypertensive drugs such as vomiting and nausea. Some of the antihypertensive drugs such as beta-blockers show extensive metabolism by CYP 450 enzymes in the intestine leading to the inactivation of an active drug or active drug metabolite [19]. 
Hence, buccal films can be used to surpass GI degradation for the delivery of antihypertensive drugs [7,20-21].

\section{LIMITATIONS}

Not feasible for high dose drugs

Buccal films have limited drug loading capacity with a polymer solution, as a high dose can lead to saturation of drug at the site of application. Drugs can be incorporated into a single dose of $20 \mathrm{mg}$ or less. Thus, buccal films are not feasible for the drugs having a single high dose, that is, more than $20 \mathrm{mg}$ [25]. However, most of the antihypertensive drugs have single-dose less than $20 \mathrm{mg}$ which makes them an ideal candidate for API for buccal films [7]. Therefore, the delivery of antihypertensive drugs can be possible in the form of buccal films.

\section{Not applicable for mucosa irritating drugs}

Some drugs such as 5-fluorouracil and methotrexate show the irritation to the mucosal membrane, thus not accessible for the formulation of buccal films [7]. Mucosal irritation can lead to damage to mucosal cell lining or any allergic reaction. However, most of the antihypertensive drugs do not show any prominent evidence of mucosal irritation in the buccal cavity [26]. Thus, buccal films can be used for the delivery of antihypertensive drugs.

\section{Dilution of the drug by saliva}

In the buccal cavity, the saliva is continuously secreted through salivary glands [12]. However, due to some physiological conditions which favor the excessive secretion of saliva, leads to dilution of the drug at a site of action where the buccal film is applied $[13,24]$. Sometimes excessive salivation can lead to lead to detachment of film from its site and swallowing of the film can also be one of the possible cases. This lead to loss of drug, as it goes into the stomach with saliva [25].

\section{Composition of mucoadhesive buccal films}

Buccal films require very few excipients as compared to other buccal drug delivery systems. Buccal films include active pharmaceutical ingredients (APIs), mucoadhesive polymer, and other excipients.

\section{API}

From any class of pharmacology drugs, any drug can be used for buccal administration but it should be compatible with buccal mucosa $[27,28]$. API should not show irritation as they can lead to mucosal layer damage in the buccal cavity. Different types of API can be efficiently incorporated in the buccal film. Drugs having high solubility and high permeability (BCS I) having a low dose can be the best candidate for buccal administration. Other class of drugs (BCS II, III, or IV) requires the prior treatment such as micronization and solid dispersion to enhance either solubility or permeability or both, before incorporating into the film [29]. The dose of a drug should be in milligrams (mg) (less than $20 \mathrm{mg} /$ day) for effective treatment. The drug can be incorporated from $5 \%-30 \% \mathrm{w} / \mathrm{w}$ of the total weight of the polymer in the buccal film $[12,13,30]$. Drugs having a single high dose are difficult to incorporate into the buccal film. As antihypertensive drugs require less dose for effective pharmacological action, they can be efficiently incorporated into the films.

\section{IDEAL PROPERTIES FOR A DRUG TO BE INCORPORATED INTO BUCCAL FILMS}

The dose should be lower than $20 \mathrm{mg}$ [25].

It does not have any significant mucosal irritation.

It should be stable in water and saliva [24].

It should show the ability to permeate the buccal mucosal layer.

\section{Mucoadhesive polymer}

For the development of a buccal delivery system, the mucoadhesive polymer is considered as one of the major formulation components of the system [12]. These polymers help to provide the intimate contact between dosage form, that is, buccal film and biological membrane, that is, buccal mucosal layer [24]. When these buccal films are applied in the buccal cavity, they attract water to hydrate the film and to provide a strong interaction between the film and the mucosal layer hence allowing for the drug to release $[14,24]$.

\section{Mucoadhesion by polymers happen in two stages [14]}

Stage I (contact stage)

Either setting, spreading, or swelling of mucoadhesive polymer produces the close contact between the polymer and mucosal membrane.

\section{Stage II (consolidation stage)}

Water provides the moisture to break the molecules and helps to form the attractive interaction bonding between polymer and membrane with reduced repulsive interaction bonding.

Ideal properties of a mucoadhesive polymer are described as follows,

1. Non-toxic and safe

2. Chemically inert

3. It should have good mechanical strength [28]

4. Compatible with saliva including its components [25]

5. It should provide immediate mucoadhesion to the buccal mucosa $[17,25,27]$

6. Compatible with API and other excipients [1].

The classification of mucoadhesive polymers with respect to its origin is described in Table 1.

The release kinetic profile of the drug from the polymer structure matrix depends on the morphology of polymer and its characteristics [34]. The mechanisms of the drug release from polymer can either by simple diffusion from polymer or degradation of polymer or both $[14,15]$. The polymer degradation takes place either by salivary enzymes or by hydrolysis. There are two types of polymer erosion, that is, surface erosion and bulk erosion [15,34]. Surface erosion is the degradation of the polymer starting from its surface either by hydrolytic or by enzymatic cleavage and bulk erosion is the degradation from the inside of the polymeric system when water penetrates the bulk of polymer mostly by hydrolytic cleavage reactions [15].

The examples of mucoadhesive polymers used in buccal films of antihypertensive drugs as shown in Table 2.

\section{Permeation enhancers}

For the development of the buccal delivery system, membrane permeation is considered as the limiting factor $[13,24]$. Thus, the study of permeation through the buccal route is essential because it is fundamental for the selection of proper permeation enhancers to improve the drug permeability. Since BCS III and IV drugs show low permeability, thus with the help of permeation enhancers the problem of permeability can be overcome $[36,48]$. The various classes of permeation enhancers used in buccal films are given in Table 3.

Table 1: Various mucoadhesive polymers described in literature

\begin{tabular}{|c|c|c|c|}
\hline $\begin{array}{l}\text { S. } \\
\text { No }\end{array}$ & $\begin{array}{l}\text { Types of } \\
\text { polymer }\end{array}$ & Examples & References \\
\hline 1. & Natural & $\begin{array}{l}\text { Sodium alginate, Tragacanth, } \\
\text { Guar gum, Xanthan gum, } \\
\text { Gelatin, Lectins, Pullulan, } \\
\text { Maltodextrin, Chitosan, Pectin, } \\
\text { Starch and modified starch }\end{array}$ & {$[1,14,25,31,34-35]$} \\
\hline 2. & Synthetic & $\begin{array}{l}\text { Polyacrylic acid, } \\
\text { Polyvinyl alcohol, } \\
\text { hydroxypropylmethylcellulose } \\
\text { hydroxyethylcellulose, } \\
\text { hydroxypropyl cellulose, } \\
\text { thiomers, Sodium } \\
\text { carboxymethylcellulose, } \\
\text { polyethylene oxide }\end{array}$ & {$[1,14,25,32-35]$} \\
\hline
\end{tabular}


Permeation enhancers interact with the buccal mucosal layer to deliver the drug from a buccal film into the systemic circulation $[14,16]$. They should be non-toxic, non-irritant, and chemically inert. They should not have any pharmacological action. The action of permeation enhancers on the buccal mucosal layer should be reversible $[36,48]$. So that after absorption of the drug, the epithelium of buccal mucosa should again retain their barrier properties [49-51]. The examples of permeation enhancers used in antihypertensive drug loaded buccal films are given in Table 4.

\section{Plasticizers}

Plasticizers are used to reduce the fragility of mucoadhesive buccal films as well as for better flexibility and strength of the film. Plasticizers can be incorporated in the film from concentration $0-20 \% \mathrm{w} / \mathrm{w}$ of the dry polymer weight [14,27]. The selection of plasticizers depends on properties of drugs and mucoadhesive polymer used [13]. The action of plasticizer is to avoid the polymer-polymer interaction as it goes in between every individual polymer strand $[27,54]$. This helps to overcome the problem of polymer deformation. Plasticizer also affects the release of the drug from the film [27]. Examples of plasticizers used in the buccal film include glycerol, low molecular weight polyethylene glycol, phthalate

Table 2: Mucoadhesive polymers used in buccal films of antihypertensive drugs described in the literature

\begin{tabular}{llll}
\hline $\begin{array}{l}\text { S. } \\
\text { No. }\end{array}$ & $\begin{array}{l}\text { Antihypertensive } \\
\text { drug }\end{array}$ & Polymer used & References \\
\hline 1. & Metoprolol & EC and HPMC & {$[7]$} \\
& & EC and chitosan & \\
2. & Methyldopa & HPMC K47 & {$[37]$} \\
3. & Lisinopril & HPMC E5 LV & {$[38]$} \\
& & HPMC E3 & \\
& & HPMC 4KM & \\
4. & Atenolol & HPMC E5 & {$[39]$} \\
5. & Clonidine & HPMC E15 & {$[40]$} \\
& hydrochloride & HPMC K4M & {$[41]$} \\
6. & Candesartan & HPMC K4M & {$[42]$} \\
7. & Valsartan & Sodium alginate & \\
& & HPC & \\
& & Tamarind gum (natural) & \\
& & Jackfruit gum (natural) & \\
8. & & HPMC K15M & {$[43]$} \\
9. & Furosemide & HPMC E464 & {$[44]$} \\
10. & Nifedipine & Sodium alginate & {$[45]$} \\
11. & Carvedilol & Chitosan \& Pectin & {$[46]$} \\
12. & Verapamil HCl & Chitosan & {$[47]$} \\
\hline
\end{tabular}

derivatives such as dimethyl and diethyl phthalate, and citrate derivatives such as tributyl, triethyl, acetyl citrate, triacetin, and castor oil [27,55]

\section{Sweetening agents}

The compounds which provide the sweet taste are called as sweetening agents or sweeteners. Sweeteners have been very important excipient for the formulation as they provide a pleasant taste to the product $[1,13,14,54]$. Low molecular weight carbohydrates such as glucose, fructose, sucrose, and dextrose are generally used as sweeteners in pharmaceutical products $[14,25]$. Nowadays, artificial sweeteners have gained the focus as an alternative sweetener in the pharmaceutical industry [25]. Sweeteners are used alone or in combination from concentration $2 \%$ to $6 \% \mathrm{w} / \mathrm{w}$ of the dry weight of the film [12]. Other than common sweeteners, alternative sweeteners which can be used in buccal films are given in Table 5 .

\section{Saliva stimulating agent (Saliva stimulator)}

Saliva helps in the disintegration and dissolution of buccal films [56]. This leads to drug release from buccal film to the mucosal layer for further absorption process [56]. Saliva stimulating agents aids in the production of an excess amount of saliva to increase the disintegration of the film leading to a quick release of drugs from the buccal film [12]. Mostly acids are used as saliva stimulators in the formulation as they trigger the immediate production of excess saliva in the buccal cavity [20]. Examples of saliva stimulants are citric acid, maleic acid, lactic acid, Vitamin C (ascorbic acid), and tartaric acid [12,25,27]. They can be used in buccal film alone or in combination from concentration $2 \%$ to $6 \% \mathrm{w} / \mathrm{w}$ dry weight of the film $[12,25]$.

\section{Flavoring agents}

Flavoring agents are used to masking the taste of bitter drugs [27]. Thus, flavoring agents are needed to enhance the flavor and mouth-feel effect in the buccal film [25]. In buccal film formulations, preferably up to $10 \% \mathrm{w} / \mathrm{w}$ flavor is allowed [14]. Flavors can be used alone or in combination according to the formulation requirements. The different types of flavorings agents with examples are given in Table 6

Sometimes flavoring agents also show the cooling effect with their significant flavor. It makes the formulation more fresh and pleasant. An examples of such a flavoring agents are menthol, monomethyl succinate which have an additional cooling effect [14].

\section{Coloring agent (colorant)}

To make the film more attractive, coloring agents are incorporated into the buccal films [12]. The concentration of colorant in the film should not exceed more than $1 \% \mathrm{w} / \mathrm{w}$ of the dry weight of the film [14]. There is various approved range of colors available that includes FD \&

Table 3: Permeation enhancers used in buccal films described in the literature

\begin{tabular}{|c|c|c|c|}
\hline S. No. & Type & Examples & References \\
\hline 1. & Surfactants & $\begin{array}{l}\text { ANIONIC: Sodium lauryl sulfate, sodium dodecyl sulfate, Dioctyl sodium sulfosuccinate } \\
\text { CATIONIC: Chitosan, Trimethyl chitosan, Cetylpyridinium chloride, L-lysine, } \\
\text { Poly-L-arginine, Benzalkonium bromide } \\
\text { NON-IONIC: Tween 80, Polysorbates, Polyoxyethylene-9-lauryl ether, } \\
\text { Polyoxyethylene-9-cetyl ether, Poloxamer, brij, Span, Myrj }\end{array}$ & {$[1,4,27,48]$} \\
\hline 2. & Derivatives of fatty acids & $\begin{array}{l}\text { Oleic acid, Caprylic acid, Sodium caprate, Propylene glycol, Methyl oleate, lauric acid, } \\
\text { linoleic acid, acylcholine, lysophosphatidylcholine, phosphatidylcholine, acylcarnitine }\end{array}$ & {$[1,21,36,48]$} \\
\hline 3. & Derivatives of bile salts & $\begin{array}{l}\text { Sodium taurocholate, Sodium deoxycholate, Sodium glycocholate, Sodium } \\
\text { glycodeoxycholate, Sodium taurodeoxycholate, Sodium taurodihydrofusidate }\end{array}$ & {$[1,14,36,48]$} \\
\hline 4. & Chelating agents & EDTA, Citric acid, Methyl salicylate, Methoxy salicylates & {$[1,14,36,48]$} \\
\hline 5. & Non-surfactants & Unsaturated cyclic ureas, Urea and it's derivatives, Azone & {$[1,36,48]$} \\
\hline 6. & Sulfoxides & Dimethyl sulfoxide, Decylmethyl sulfoxide & {$[1,14,36,48]$} \\
\hline 7. & Inclusion complexes & Cyclodextrin & {$[14,28,36]$} \\
\hline 8. & Thiolated polymers & $\begin{array}{l}\text { Chitosan-4-thiobutylamide, Chitosan-4-thiobutylamide/GSH, Chitosan-cysteine, } \\
\text { Poly-(acrylic acid)-homocysteine, Polycarbophil-cysteine, Polycarbophil-cysteine/GSH }\end{array}$ & {$[27,48]$} \\
\hline 11. & Others & Aprotinin, Dextran sulfate, various alkyl glycosides, Polyvinylpyrrolidone, Menthol & {$[14,52]$} \\
\hline
\end{tabular}


C colors, EU colors, natural colors or pigments, metal oxides such as titanium oxide, zinc oxide, and so forth [24,25].

\section{METHODS OF PREPARATION}

Mucoadhesive buccal films can be prepared by following methods-

1. Solvent casting method

2. Hot melt extrusion (HME) method.

\section{Solvent casting method}

The solvent casting method is the most widely accepted manufacturing process utilized for the production of films [12]. It is a very simple and easy method which makes it a more conventional method than other methods. In this method, the required quantity of polymer is dissolved in distilled water. On the other hand, active pharmaceutical ingredients and other excipients are dissolved in a suitable solvent system. Afterward, both solutions are mixed and stirred to form a homogeneous mixture. This resultant solution is called as "casting solution." The casting solution is then diffused on the Petri dish and kept in a hot air oven for drying at the optimum temperature (mostly $40^{\circ} \mathrm{C}$ ). After drying, that Petri plate is kept in a desiccator for $24 \mathrm{~h}$. Afterward, the dried film is removed from the Petri dish and cut into the required dimensions [25].

The solvent casting method involves the steps which are described below [25,58-63],

- Step 1: Preparation of casting solution

- Step 2: Deaeration of casting solution

- Step3: Transfer of deaerated casting solution into the mold

- Step 4: Drying of the solution

- Step 5: Cutting of dried film into appropriate dimensions

- Step 6: Packaging of formed films

Deaeration is considered as the most critical step of the solvent casting method. If the films are formed in a solution that has entrapped air in it then it leads to surface non-uniformity as well as uneven thickness of the film. One of the major disadvantages of the solvent casting method is the presence of organic solvent impurities in the films [25]. One of the examples of the mucoadhesive buccal film of the antihypertensive drug prepared by the solvent casting method is buccoadhesive polymer matrix films of Losartan using HPMC polymer [49].

\section{HME method}

HME is one of the techniques which involve the molecular dispersion of drug (API) into a polymer matrix [63]. This method includes the

Table 4: Permeation enhancers used in buccal films of antihypertensive drugs described in the literature

\begin{tabular}{llll}
\hline S. No. & $\begin{array}{l}\text { Antihypertensive } \\
\text { drug }\end{array}$ & $\begin{array}{l}\text { Permeation } \\
\text { enhancer used }\end{array}$ & References \\
\hline 1. & $\begin{array}{l}\text { Clonidine } \\
\text { hydrochloride }\end{array}$ & $\begin{array}{l}\text { Citric acid } \\
\text { Sodium lauryl sulfate }\end{array}$ & {$[40]$} \\
2. & Methyldopa & PVP K-30 & {$[38]$} \\
3. & Candesartan & Propylene glycol & {$[41]$} \\
4. & Losartan & Propylene glycol & {$[49]$} \\
5. & Valsartan & Propylene glycol & {$[42]$} \\
6. & Enalapril maleate & PVP & {$[53]$} \\
\hline
\end{tabular}

instrument called as hot melt extruder [13]. In this method, the drug and polymer are fed into hopper and passed it to an extruder. In the extruder, the drug and polymer with other excipients are mixed, ground, and heated to form a homogeneous molten mixture. This mixture is then kneaded and went through an orifice to mold under specified pressure and temperature to shape the films. The formed product is cooled and packed in suitable packaging material [63-65]. This method does not involve any use of a solvent which makes it a solvent-free method. It also provides better uniformity of contents than the solvent casting method [25]. The two major limitations of this method include only limited polymers that can be used and it is not suitable for thermolabile molecules such as proteins which might degrade $[25,64]$. Examples of film-forming agents that can be used in HME are polyethylene oxide, maltodextrin, hydroxypropyl cellulose (HPC), hydroxypropylmethylcellulose (HPMC), pullulan, starch, and modified starch, etc. [64]. One of the examples of a mucoadhesive buccal film of the antihypertensive drug prepared by hot-melt extrusion method is cellulosic hot-melt extruded films containing Lidocaine using HPC and HPMC polymer [66].

\section{CHARACTERIZATION OF MUCOADHESIVE FILMS}

The mucoadhesive buccal films should be evaluated to determine their quality and efficiency. There are various tests to be performed to characterize the buccal films which are described below-

\section{Physical appearance and surface texture} (Evaluation of organoleptic properties)

Organoleptic properties such as color, flavor, and taste should be primarily evaluated. It is mainly done by visual inspection of prepared buccal films. The errors in manufacturing processes can lead to defects in buccal film formulation. This may include defects in the surface texture of films. An uneven surface of buccal films is the indication of non-uniformity of contents and fault in developed films. Good taste, color, and surface texture provide more patient accessibility. The taste of the film can be determined using E-tongue software $[14,67,68]$.

\section{Surface $\mathbf{p H}$}

Inappropriate surface $\mathrm{pH}$ of the buccal film can lead to irritation of buccal mucosa in vivo. Therefore, the determination of surface $\mathrm{pH}$ is considered as one of the important evaluation parameters. The $\mathrm{pH}$ of the buccal mucosa is around $\mathrm{pH}$ 6.2-7.5. Thus, buccal film should also have the $\mathrm{pH}$ range as that of the $\mathrm{pH}$ of buccal mucosa to avoid mucosal irritation. In this method, the film is placed in the petri dish and $0.5 \mathrm{ml}$ of distilled water is put on the surface of the film and kept it for $1.0 \mathrm{~h}$. Then, the $\mathrm{pH}$ is measured by touching the electrode tip of pH-meter in contact with the moistened surface of the buccal film for about $1.0 \mathrm{~min}[14,69-71]$.

\section{Wettability}

The wettability of the film is determined by the measurement of the contact angle. As contact angle affects the wetting property, disintegration, and dissolution time of the film. A special instrument with a digital camera is used to determine the contact angle. A drop of bidistilled water is placed on the surface of the film for few seconds at ambient conditions. Then, further analysis for determination of contact angle is done by software.

Table 5: Different types of alternative sweeteners

\begin{tabular}{|c|c|c|c|c|}
\hline S. No. & Type of sweetener & Description of sweetener & Examples & References \\
\hline 1. & Nutritive sweetener & $\begin{array}{l}\text { They are less caloric and sweet than sugar but have } \\
\text { most of the properties like sugars. Thus they are } \\
\text { also used as a bulking agent in sugar-free products. }\end{array}$ & $\begin{array}{l}\text { Sorbitol, Mannitol, Xylitol, Maltitol, Lactitol, } \\
\text { Erythritol }\end{array}$ & {$[14,25]$} \\
\hline 2. & $\begin{array}{l}\text { Non-nutritive } \\
\text { sweetener }\end{array}$ & $\begin{array}{l}\text { They are sweeter than sugar and required in least } \\
\text { quantities. }\end{array}$ & $\begin{array}{l}\text { Fruit sugars, Aspartame, Sodium saccharin, } \\
\text { Glycyrrhizin, Stevioside, Cyclamate }\end{array}$ & {$[14,25]$} \\
\hline 3. & Artificial sweetener & $\begin{array}{l}\text { They are prepared synthetically and now commonly } \\
\text { used as they are less carcinogenic. }\end{array}$ & $\begin{array}{l}\text { Aspartame, Sodium saccharin, Sorbitol, } \\
\text { Mannitol, Acebilfame-K }\end{array}$ & {$[14,25]$} \\
\hline
\end{tabular}


Table 6: Different types of flavors

\begin{tabular}{llll}
\hline S. No. & Type of flavor & Examples & References \\
\hline 1. & Essential oils & $\begin{array}{l}\text { Peppermint, Sweet mint, } \\
\text { Wintergreen, Menthol }\end{array}$ & {$[14,25,27]$} \\
2. & Citrus fruit flavor & Lemon, Orange & {$[14,25,27]$} \\
3. & Fruit essences & $\begin{array}{l}\text { Apple, Strawberry, } \\
\text { Raspberry, Cherry, }\end{array}$ & {$[14,25,27]$} \\
& & Pineapple & \\
\hline
\end{tabular}

To obtain well-defined results, a minimum of twenty measurements should be performed for each film formulation $[14,72]$.

\section{Transparency}

The optical property of the buccal film is determined by measuring transparency using a UV-visible spectrophotometer. The film is directly placed in the spectrophotometer magnetic cell and an empty cell is kept as a reference. Transparency of film is determined by measuring transmittance at $660 \mathrm{~nm}[14,73]$. Transparency is calculated using formula-

$$
\text { Transparency }=\left(\mathrm{T}_{660} / \mathrm{b}\right)=-\varepsilon \mathrm{c}
$$

Where, $\mathrm{T}_{660}$ is transmittance at $660 \mathrm{~nm}, \mathrm{~b}$ is film thickness, c is concentration, and $\varepsilon$ is molar absorptivity

\section{Swelling index}

Here, the pre-weighted dry film is kept in a Petri dish containing phosphate buffer $\mathrm{pH} 6.6$ at $37^{\circ} \mathrm{C}$ for a pre-determined time (t). The film will be swelled. After time " $t$," the film is separated from phosphatebuffered solution (PBS) and wiped with absorbent tissue paper to remove an excess of water from the surface. Then, swelled film is reweighted [13-14,28,74,75]. The swelling index is determined using formula-

$$
\text { S.I. }=\left[\left(\mathrm{W}_{2}-\mathrm{W}_{1}\right) / \mathrm{W}_{1}\right] \times 100
$$

Where, S.I. is swelling index of film, $\mathrm{W}_{2}$ is weight of swollen film at time "t," $\mathrm{W}_{1}$ is weight of dry film at zero time

\section{Percent erosion of polymer}

The erosion characteristics of films are determined by measuring the erosion of the polymer. Here, the dry film is kept in a Petri dish containing simulated saliva for a pre-determined time $(\mathrm{t})$. The polymer will undergo erosion processes. After time " $\mathrm{t}$," the remaining film is removed from the Petri dish, dried, and weighed again [53]. The percent erosion of polymer is determined using formula-

$$
\% \text { erosion }=\left[\left(\mathrm{W}_{1}-\mathrm{W}_{2}\right) / \mathrm{W}_{1}\right] \times 100
$$

Where, $W_{1}$ is original weight of dry film at zero time and $W_{2}$ is remaining weight of film at time " $\mathrm{t}$ "

\section{Thickness}

The buccal film should have a uniform and optimum thickness with a range of 5-200 $\mu \mathrm{m}$. Proper thickness ensures the accurate dose and good absorption of the drug. Thickness can be measured either using an electronic digital micrometer screw gauge or calibrated digital Vernier caliper. To determine the thickness, different positions such as four corners and the center of a film should be considered $[13,14,67,77]$.

\section{Weight variation}

The optimum sized films are cut from different positions of casting film. The individual films are weighed using electronic weighing balance and the average weight is calculated. The weight variation is calculated by subtracting the average weight of the film from the individual weight of the film. The large weight variation indicates improper method and also non-uniform content in the film $[12,14,78,79]$.

\section{Percent moisture loss}

Percent moisture loss is an indication of film integrity and physical stability. The accurately weighed films are kept in a desiccator containing fused anhydrous calcium chloride for 3 days leading to moisture loss. After 3 days, the films are taken out and weighed again $[14,84,85]$. The percent moisture loss can be determined using formula-

$$
\% \text { moisture loss }=\left[\left(\mathrm{W}_{1}-\mathrm{W}_{2}\right) / \mathrm{W}_{1}\right] \times 100
$$

Where, $W_{1}$ is initial weight of dry film and $W_{2}$ is final weight of film

\section{Percent moisture absorption}

The pre-weighted films are kept in desiccator having $100 \mathrm{ml}$ of a saturated solution of ammonium chloride up to $96 \%$ humidity for $72 \mathrm{~h}$. After $72 \mathrm{~h}$, films are removed and weighed again [14,86,87]. The percent moisture absorption is determined using formula-

$$
\% \text { moisture absorption }=\left[\left(\mathrm{W}_{2}-\mathrm{W}_{1}\right) / \mathrm{W}_{1}\right] \times 100
$$

Where, $W_{1}$ is initial weight of dry film and $W_{2}$ is final weight of film

\section{Folding endurance}

Folding endurance is considered as a measure of the brittleness of film. It is done by repeatedly folding optimum sized (generally $2 \times 2 \mathrm{~cm}^{2}$ or $3 \times 3 \mathrm{~cm}^{2}$ ) film under standard conditions until it breaks or visible crack observed $[13,14,83,88]$.

\section{Tear resistance}

Tear resistance is considered to measure maximum resistance offered by the film at a rate up to $50 \mathrm{~mm} / \mathrm{min}$ before the rupturing of the film when load or force is applied. It is performed either using Elmendorf tear tester (pendulum method) or in the tensile testing machine $[14,82]$.

\section{Tensile strength}

Tensile strength is the maximum stress or force applied to rupture the film by stretching. The film is placed between the clamps lever of the instrument and additional force at a rate of $2 \mathrm{~mm} / \mathrm{min}$ was applied to film $[14,73,90-92]$. At tearing time, a load of failure (F) is measured.

$$
\text { Tensile strength }=[\mathrm{F} /(\mathrm{t} \times \mathrm{w})] \times 100
$$

Where, $\mathrm{F}$ is weight or load of failure, $\mathrm{t}$ is thickness of film and $\mathrm{w}$ is width of film

The hard and brittle film has high tensile strength [14]

\section{Percent elongation}

Elongation capacity of the film is expressed by stretching capacity after applying stress to deform the film before it gets broken $[14,80]$. The percent elongation is calculated using formula-

$$
\% \text { elongation }=\left[\left(\mathrm{L}_{2}-\mathrm{L}_{1}\right) / \mathrm{L}_{1}\right] \times 100
$$

Where, $\left(L_{2}-L_{1}\right)$ is increased length of film and $L_{1}$ is initial length of film

\section{Interaction study}

Drug-polymer-excipient interactions should be considered while characterization for the development of an effective buccal film. It is done either using the FTIR spectrometer using the $\mathrm{KBr}$ pellet method to record the FTIR spectrum or by differential scanning calorimetry to record thermograms of sample films $[14,81]$.

\section{Drug content uniformity}

It is done by dissolving the buccal film in $100 \mathrm{ml}$ of an appropriate solvent system for complete solubilization of film with occasional shaking. From that solution, $5 \mathrm{ml}$ of solution is withdrawn and diluted using a pre-determined solvent system to form a final resultant solution. This resultant solution is filtered through Whatman filter paper and analyzed using analytical techniques such as HPLC, HPTLC, and LC-MS $[14,56,86]$. 
XRD study

$\mathrm{XRD}$ analysis is done to determine the physical form, that is, crystalline or amorphous of drug molecules inside the films. It is performed on an X-ray diffractometer to record XRD transmission diffractogram (XRD patterns) over the diffraction angle range of $2 \theta$ at a scan rate of $4^{\circ} / \mathrm{min}$ [31].

\section{Scanning electron microscopy (SEM) analysis}

Analysis of outer surface morphology of buccal film is done by SEM using a scanning electron microscope with appropriate applied voltage. It also helps to determine drug-excipient interactions [14,93].

\section{In vitro disintegration time study}

For better absorption, the buccal film should disintegrate in the oral mucosa. In vitro disintegration time test has been described in USP. The film is placed in a Petri dish containing 10-15 ml of PBS having $\mathrm{pH}$ 6.6. Then, the Petri dish is kept in an incubator shaker at a speed of $50 \mathrm{rpm}$ at $37^{\circ} \pm 1^{\circ} \mathrm{C}$. The time at which the film starts to break is recorded as disintegration time $[14,84,86]$.

\section{In vitro dissolution study}

Dissolution test apparatus type II (USP II) (Paddle type) is used to study the in vitro drug release profile using isotonic PBS pH 6.6 at $50 \mathrm{rpm}$ at $37^{\circ} \pm 1^{\circ} \mathrm{C}$ for time period of $8 \mathrm{~h}$ [94]. The film is pasted to a glass disk with cyanoacrylate adhesive. This assembly is placed at bottom of the dissolution flask. The flask is filled with $900 \mathrm{ml} \mathrm{PBS} \mathrm{pH} \mathrm{6.6.} \mathrm{The} \mathrm{sample}$ (aliquot) of $5 \mathrm{ml}$ is taken out at regular intervals and replaced with fresh PBS pH 6.6. Then, the aliquot is filtered, diluted with PBS pH 6.6 and analyzed by spectrophotometer $[14,76,81]$.

\section{Kinetic release data analysis}

Various kinetic models such as the zero-order, the first order, the Higuchi, the Hixon-Crowell cube root law, and the Korsmeyer-Peppas model are used to analyze the drug release mechanism from the buccal films. The readings of dissolution data are put in the respective mathematic models to determine the drug release kinetics [25].

\section{In vitro metabolism studies}

The development of cell culture models for the study of drug metabolism is in process. In the literature, they had attempted with hamster cheek cultured cells as hamster cheek cells narrowly mimic human mucosa cells which make it a suitable model for prediction of permeability through the human buccal mucosa [89].

\section{Ex vivo mucoadhesion test/ residence test}

The efficiency of mucoadhesive buccal films is dependent on how much time it is able to adhere or stick to the buccal mucosa where the film is subjected before it dissolves or deteriorates away. For the particularly sustained release of a drug, it is expected that the film remains at the site of application until the maximum drug is released. The mucoadhesion time of the buccal film is the time required for the film to detach or erode from freshly excised porcine buccal mucosa (model membrane) onto which the buccal film is applied. The film is moistened with simulated saliva solution and placed on buccal mucosa. Then with little force for about 10-20 s, the initial contact between the film and mucosal membrane is generated on the left pan. In the right pan, drop wise water is added until the film is detached from the mucosal membrane. The weight of water in the right pan is considered as bioadhesive strength. The average of bioadhesive strength of three buccal films is considered for further calculation [41,42,46,49,95-97]. The mucoadhesive force can be determined by a formula-

\section{Mucoadhesive force $=($ Bioadhesive strength $/ 1000) \times 9.81$}

\section{Ex vivo mucoirritation test}

It is done to observe the pathological changes in buccal cell membrane morphology and their structure after the application of buccal films. It is performed by using a freshly excised bovine buccal mucosal membrane. The sample film is prepared with eosin pigment and cut in a thickness of $4 \mu \mathrm{m}$. The sample film without the drug is considered as a controlled group while sample film with the drug as a treated group. Then a photograph of controlled untreated and drug-containing buccal film subject to simple diffusion in the bovine buccal mucosal membrane as observed [42].

\section{Ex vivo permeation study}

The permeation studies of buccal films through a freshly excised layer of sheep buccal mucosa are carried out using modified Franz diffusion cell. In the donor compartment, the film is wetted with PBS pH 6.6 and placed in contact with a buccal mucosal membrane and filled with $5 \mathrm{ml}$ of PBS pH 6.6. The receptor compartment is filled with isotonic PBS pH 6.6 and stirred using a magnetic stirrer at ambient conditions with a speed of $50 \mathrm{rpm}$. The samples $(1 \mathrm{ml})$ are collected at suitable time intervals, filtered, diluted with $\mathrm{PBS} \mathrm{pH}$ 6.6, and then analyzed by a suitable analytical method to determine the percent drug permeated through the buccal mucosa $[14,41,98,99]$.

\section{In vivo study}

Since in vitro testing lacks the systemic evaluation and the effect of other physiological factors on the overall performance of active ingredient from the buccal film. In general, an in vivo study is first performed on animal models such as rats, rabbits, dogs, and pigs before testing on humans. The blood samples are withdrawn at regular intervals and centrifuged to get a plasma sample. The plasma is filtered and diluted with an appropriate solvent. Then, it is analyzed using a suitable analytical technique such as the HPLC system [46].

\section{Stability study in human saliva}

It is done using natural human saliva. The human saliva samples of 10 healthy volunteers (18-40 years age group) are collected. The film is placed in a Petri dish containing $5 \mathrm{ml}$ of human saliva and kept it at ambient conditions. At regular intervals, the morphology and organoleptic properties of the buccal film are observed. If no physical change in the film is observed, then it indicates the film will be more stable in the buccal cavity throughout the period of its residence time $[14,73,82-84,86]$.

\section{Stability study as per ICH guidelines}

As per ICH guidelines for the stability of the formulation, the films are kept at $40^{\circ} \mathrm{C}$ and $75 \%$ relative humidity to observe the effect of temperature and humidity on buccal films for 3 months. At the time of $1^{\text {st }}, 2^{\text {nd }}$, and $3^{\text {rd }}$ months, the films are observed for drug content by performing drug assay as well we for investigation in a specific change in prepared films which includes a change in color and texture. If non-complied assay and specific changes are observed, the films are subjected to stability issues in storage conditions $[14,83,84,86]$.

\section{EXAMPLES OF MUCOADHESIVE BUCCAL FILMS CONTAINING ANTIHYPERTENSIVE DRUGS}

\section{Carvedilol hydrochloride}

Carvedilol is from the $\beta$-blocker class of drugs used for the treatment of hypertension by reducing the total peripheral resistance. Carvedilol hydrochloride shows $25-35 \%$ of bioavailability on oral administration due to its high hepatic first-pass metabolism. Thus, an approach of administration of carvedilol through buccal film had been performed by Amanpreet Kaur et al. to overcome the problems. They had developed buccal patches of carvedilol $\mathrm{HCl}$ using natural polymers (chitosan and pectin) as mucoadhesive polymer showing improved bioavailability. They concluded that using interpolymers complex of chitosan and pectin can be used to formulate the buccal films of carvedilol [46].

\section{Nitrendipine}

Nitrendipine is from calcium channel blockers class of drugs used for the treatment of hypertension. Since nitrendipine shows extensive hepatic first-pass metabolism on oral administration causing 10-15\% bioavailability. As an alternative to oral administration, the approach of nitrendipine in buccal films had been carried out by Nappinnai et al. to get better results. They had prepared buccal films of nitrendipine using HPC as a mucoadhesive polymer having better bioavailability than conventional solid oral dosage forms [100]. 


\section{Valsartan}

Valsartan is an angiotensin II receptor antagonist class of drugs used in the therapy of hypertension. Valsartan undergoes high first-pass metabolism leading to low oral bioavailability of 20$25 \%$. To overcome the problem, an attempt for the development of mucoadhesive buccal films of valsartan had been performed by Rani and Madhavi. They had developed the buccal film of valsartan using natural polymer, that is, jackfruit gum to provide sustained release formulation with better bioavailability. They concluded that the bioerodable buccal films can be used for the effective delivery of active agent with prominent IVIVC [42].

\section{Enalapril maleate}

Enalapril is the ACE inhibitor class of drugs used in the treatment of hypertension. Enalapril maleate shows $60-70 \%$ absorption but $40-30 \%$ oral bioavailability. The low bioavailability is a result of high hepatic first-pass metabolism. Thus formulation of the mucoadhesive buccal film of enalapril maleate had been performed by Semalty et al. using sodium carboxymethylcellulose and hydroxyethylcellulose as mucoadhesive polymers to enhance the bioavailability and effective treatment [53].

\section{Furosemide}

Furosemide is the loop diuretic class of drugs used in the management of hypertension as it inhibits reabsorption of sodium, chloride, and potassium ions with increased urine flow. Furosemide belongs to BCS Class IV drugs, thus it shows low solubility and low permeability. In literature, Alopaeus et al. had attempted to develop a mucoadhesive buccal film of furosemide using Soluplus ${ }^{\circledR}$ (a mixture of PEG 600, vinyl caprolactam and vinyl acetate) as a solubilizer and the film-forming agent showing enhanced absorption and bioavailability by ex vivo permeation studies using TR146 epithelial cell linings [44].

\section{CONCLUSION}

The approach of mucoadhesive buccal films has been provided various advantages for the administration of antihypertensive drugs to minimize the problem of low bioavailability and GI degradation. Various antihypertensive drugs have been incorporated into mucoadhesive buccal films to provide effective management of hypertension. An antihypertensive drug with different excipients is used to formulate and develop mucoadhesive buccal films using different techniques. These buccal films are characterized by various evaluation tests to estimate the quality, efficiency, and performance through mucoadhesive delivery of proposed buccal films. Through literature, it has been seen that various mucoadhesive buccal films containing antihypertensive drugs are developed with improved absorption and bioavailability.

\section{ACKNOWLEDGMENT}

The authors are thankful toward Gaurang Sawant along with the staff of H.K. College of Pharmacy for guiding for the preparation of this manuscript.

\section{AUTHORS CONTRIBUTION}

All authors have taken part in the design and drafting the article and revising it critically for important intellectual content as well as approval of the final version.

\section{CONFLICT OF INTERESTS}

Declared none.

\section{AUTHORS FUNDING}

None.

\section{REFERENCES}

1. Puratchikody A, Prasanth VV, Mathew ST, Kumar BA. Buccal drug delivery: Past, present and future-a review. Int J Drug Deliv 2011;3:171-84.
2. Shojaei AH, Chang RH, Guo X, Burnside BA, Couch RA. Systemic drug delivery via the buccal mucosal route. Pharm Tech 2001;6:70-81.

3. Algabbani FM, Algabbani AM. Treatment adherence among patients with hypertension: Findings from a cross-sectional study. Clin Hypertens 2020;26:18.

4. Onuh JO, Aliani M. Metabolomics profiling in hypertension and blood pressure regulation: A review. Clin Hypertens 2020;26:23.

5. Ramsay LE, Williams B, Johnstn GD, MacGregor GA, Poston L, Potter JF, et al. British hypertension society guidelines for hypertension management 1999: Summary. BMJ 1999;319:635-8.

6. Neal M. Medical Pharmacology at a Glance. $7^{\text {th }}$ ed. New York: John Wiley \& Sons Inc.; 2012. p. 36-43.

7. Gorle A, Patil P, Bhaskar R, Ola M. Development and evaluation of buccal film containing antihypertensive agents. Pharm Innov J 2015;4:53-60

8. Beevers G, Lip GY, O'Brien E. ABC of hypertension: The pathophysiology of Hypertension. BMJ 2001;322:912-6.

9. Tortora GJ, Derrickson B. Principles of Anatomy and Physiology. $14^{\text {th }}$ ed. New York: John Wiley \& Sons Inc.; 2014. p. 729-98.

10. Waugh A, Grant A. Ross and Wilson Anatomy and Physiology in Health and Illness. $13^{\text {th }}$ ed. New York: Elsevier; 2015a. p. 131-5.

11. Waugh A, Grant A. Ross and Wilson Anatomy and Physiology in Health and Illness. $13^{\text {th }}$ ed. New York: Elsevier; 2015b. p. 352-3.

12. Madhavi BR, Murthy VS, Rani AP, Gattu DK. Buccal film drug delivery system-an innovative and emerging technology. J Mol Pharm Org Process Res 2013;1:3.

13. Rao NG, Shravani B, Reddy MS. Overview on buccal drug delivery systems. J Pharm Sci Res 2013;5:80-8.

14. Rajaram DM, Laxman SD. Buccal mucoadhesive films: A review. Sys Rev Pharm 2017;8:31-8.

15. Brahmankar DM, Jaiswal SB. Biopharmaceutics and Pharmacokinetics-A Treatise. $4^{\text {th }}$ ed. New Delhi: Vallabh Prakashan; 2005. p. 5-75.

16. Shojaei AH, Chang RK, Guo X, Burnside BA, Couch RA. Systemic drug delivery via the buccal mucosal route. Pharm Tech 2001;25:70-81.

17. Verma S, Kumar N, Sharma PK. Buccal film: An advance technology for oral drug delivery. Adv Biol Res 2014;8:260-7.

18. Saurabh R, Malvia R, Sharma PK. Trends in buccal films: Formulation, characteristics, recent studies and patents. Eur J Appl Sci 2011;3:93-101.

19. Mehner W, Mader K. Solid lipid nanoparticles: Production, characterization and applications. Adv Drug Deliv Rev 2001;47:165-96.

20. Chang R, Goo X, Burnside BA, Couch R. Fast dissolving tablet. Pharm Tech 2000;24:52-8.

21. Kuchekar BS, Badhan AC, Mahajan HS. Mouth dissolving tablets. A novel drug delivery system. Pharm Times 2003;35:7-9.

22. Raju KN, Velmurugam S, Deepika B, Vinushitha S. Formulation and in vitro evaluation of buccal tablets of metoprolol tartarate. Int J Pharm Pharm Sci 2011;3:239-49.

23. Sravanthi RR, Rajalakshmi R, Moorthy SB, Rupangada V, Sudha ER. Muoadhesive buccal films: An innovative drug delivery system. Int J Pharm Tech Res 2014;6:1665-78.

24. Shinde P, Salunkhe V, Mahdum C. Buccal film: An innovative dosage form designed to improve patient compliance. Int J Pharm Chem Sci 2012;1:1262-78

25. Jagtap VD. Buccal film-a review on novel drug delivery system. Int J Res Rev 2020;7:17-28.

26. Zisaki A, Miskovic L, Hatzimanikatis V. Antihypertensive drugs metabolism: An update to pharmacokinetic profiles and computational approaches. Curr Pharm Des 2015;21:806-22.

27. Dave V, Mishra A. A review on promising novel drug delivery systembio-adhesive drug delivery system. Curr Res Pharm Sci 2017;7:69-78.

28. Reddy PC, Chaitanya KS, Rao YM. A review on bio-adhesive buccal drug delivery systems: Current status of formulation and evaluation methods. DARU 2011;19:385-403.

29. de Caro V, Ajovalasit A, Sutera FM, Murgia D, Sabatino MA, Dispenza C. Development and characterization of an amorphous solid dispersion of Furosemide in the form of a sublingual bioadhesive film to enhance bioavailability. Pharmaceutics 2017;9:22.

30. Hanif M, Zaman M, Chaurasiya V. Polymers used in buccal film: A review. Des Monomers Polym 2015;18:105-11.

31. Clark MA, Hirst BH, Jepson MA. Lectin-mediated mucosal delivery of drugs and microparticles. Adv Drug Deliv Rev 2000;43:207-23.

32. Leitner VM, Walker GF, Bernkop-Schnurch A. Thiolated polymers: Evidence for the formation of disulphide bonds with mucus glycoproteins. Eur J Pharm Biopharm 2003;56:207-14.

33. Bernkop-Schnurcg A. Thiomers: A new generation of mucoadhesive polymers. Adv Drug Deliv Rev 2005;57:1569-82. 
34. Woertz C, Preis M, Breitkreutz J, Kleinebudde P. Assessment of test methods evaluating mucoadhesive polymers and dosage forms: An overview. Eur J Pharm Biopharm 2013;85:843-53.

35. Krishnaveni M, Chandana AV, Shanmugam V, Prakash P, Sandeep S, Radhika KV. Bioadhesive formulation-buccal films. Int J Res Pharm Life Sci 2013;1:48-58.

36. Moser K, Kriwet K, Naik A, Kalia YN, Guy RH. Passive skin penetration enhancement and its quantification in vitro. Eur $\mathrm{J}$ Pharm Biopharm 2001;52:103-12.

37. Ganaie MU, Mohan G, Sharma S, Din SM, Shukla TP, Hassan I. Formulation development and evaluation of mucoadhesive buccal film of methyldopa. J Glob Trends Pharm Sci 2014;5:1893-904.

38. Prabhu P, Dubey A, Kamath K. Formulation and evaluation of fastdissolving film of lisinopril. Egypt Pharm J 2015;14:56-64.

39. Sanjay P, Gupta NV, Gowda DV, Sivadasu P. Formulation and evaluation of oral disintegrating film of atenolol. Asian J Pharm Clin Res 2018;11:8.

40. Dangre PV, Phad RD, Surana SJ, Chalikwar SS. Quality by design $(\mathrm{QbD})$ assisted fabrication of fast dissolving buccal film for clonidine hydrochloride: Exploring the quality attributes. Adv Polym Tech 2019;2019:3682402

41. Malpure DR, Deore SL. Development and characterization of buccal film of candesartan. Pharm Methods 2016b;7:75-88.

42. Rani P, Madhavi R. Formulation and evaluation of sustained release mucoadhesive buccal films of valsartan using natural mucoadhesive polymers. World J Pharm Res 2018;7:1637-61

43. Lohani A, Prasad N, Arya RK. Formulation and characterization of mucoadhesive buccal films of ranitidine hydrochloride. Int J Pharm Sci Res 2011;2:2457.

44. Alopaeus JF, Hellfritzsch M, Gutowski T, Scherlie R, Almeida A, Sarmento B, et al. Mucoadhesive buccal films based on a graft co-polymer-a mucin-retentive hydrogel scaffold. Eur J Pharm Sci 2019;142:105142

45. Save T, Shah UM, Ghamande AR, Venkatachalam P. Comparative study of buccoadhesive formulations and sublingual capsules of nifedipine. J Pharm Pharmacol 1994;46:192-5.

46. Kaur A, Kaur G. Mucoadhesive buccal patches based on interpolymer complexes of chitosan-pectin for delivery of carvedilol. Saudi Pharm J 2012;20:21-7.

47. Deshmane SV, Channawar MA, Chandewar AV, Joshi UM, Biyani KR. Chitosan based sustained release mucoadhesive buccal patches containing verapamil HCl. Int J Pharm Pharm Sci 2009; 1:216-29.

48. Dodla S, Velmurugan S. Buccal penetration enhancers-an overview. Asian J Pharm Clin Res 2013;6:39-47.

49. Koland $M$, Charyulu NR. Design and in vivo evaluation of buccoadhesive hydrophilic polymer matrix films of losartan potassium. Indian J Pharm Educ Res 2016;50:S115-24

50. Zhai H, Maibach HI. Occlusion vs. skin barrier function. Skin Res Technol 2002;8:1-6.

51. Williams AC, Barry BW. Penetration enhancers. Adv Drug Deliv Rev 2012;64:128-37.

52. Lavan DA, McGuire T, Langer R. Small-scale systems for in vivo drug delivery. Nat Biotechnol 2003;21:1184-91.

53. Semalty A, Semalty M, Nautiyal U. Formulation and evaluation of mucoadhesive buccal films of enalapril maleate. Indian J Pharm Sci 2010;72:571-5.

54. Yajaman S, bandyopadhyay AK. Buccal bioadhesive drug delivery-a promising option for orally less efficient drugs. J Control Release 2006;114:15-40.

55. McIndoe LM, Rowe RC, Sheskey PJ, Owen SC. Handbook of Pharmaceutical Excipients. London: Pharmaceutical Press; 2006. p. 128-30.

56. Patricia DV, Maria AN, Antonio AS. Saliva composition and function: A comprehensive review. J Adv Pharm Educ Res 2013;3:1-15.

57. Neelagiri R, Reddy MS, Rao NG. Buccal patch as drug delivery system: An overview. Int J Curr Pharm Res 2013;5:42-7.

58. Arya A, Chandra A, Sharma V, Pathak K. Fast dissolving oral film: An innovative drug delivery and dosage form. Int J Chemtech Res 2010;2:576-83

59. Corniello CM. Quick dissolving strips: From concept to commercialization. Pharm Tech 2006;6:68-71.

60. Boateng JS, Auffret AD, Matthews KH, Humphrey MJ, Stevens HN, Eccleston GM. Characterization of freeze-dried wafers and solvent evaporated films as potential drug delivery systems to mucosal surfaces. Int J Pharm 2010;389:24-31.

61. Cilurzo F, Cupone IE, Minghetti P, Selmin F, Montanari L. Fast disilving films made of maltodextrins. Eur J Pharm Biopharm 2008;70:895-900.
62. Patel VM, Prajapati BG, Patel MM. Design and characterization of chitosan-containing mucoadhesive buccal patches of propranolol hydrochloride. Acta Pharm 2007;57:61-72

63. Maniruzzaman M, Boateng JS, Snowden MJ, Douroumis D. A review of hot-melt extrusion: Process technology to pharmaceutical products. ISRN Pharm 2012;2012:436763.

64. Jani R, Patel D. Hot melt extrusion: An industrially feasible approach for casting orodispersible film. Asian J Pharm Sci 2015;10:292-305.

65. Repka MA, Munjal M, Elsohly MA, Ross SA. Temperature stability and bioadhesive properties of $\Delta^{9}$-tetrahydrocannabinol incorporated Hydroxypropylcellulose polymer matrix systems. Drug Dev Ind Pharm 2006;32:21-32

66. Repka MA, Gutta K, Prodduturi S, Munjal M, Stodghill SP. Characterization of cellulosic hot-melt extruded films containing lidocaine. Eur J Pharm Biopharm 2005;59:189-96.

67. Davidovich-Pinhas M, Bianco-Peled H. Mucoadhesion: A review of characterization techniques. Expert Opin Drug Deliv 2010;7:259-71.

68. Li L, Naini V, Ahmed SU. Utilization of a modified special-cubic design and an electronic tongue for bitterness masking formulation optimization. J Pharm Sci 2007;96:2723-35.

69. Chinna RP, Madhusudan RY. Buccal drug delivery systems. In: Rao YM, Jithan AV, editors. Advances in Drug Delivery. Vol. 1. PharmaMed Press; 2010. p. 139-210.

70. Dixit RP, Puthil SP. Oral strip technology: Overview and future potential. J Control Release 2000;139:94-107.

71. Bottenberg P, Cleymaet R, Mujnek CD, Remon JP, Coomans D, Slop $\mathrm{D}$. Development and testing of bioadhesive, fluoride-containing slowrelease tablets for oral use. J Pharm Pharmacol 1991;43:457-64.

72. Chinna RP, Ramesh G, Vamshi VY, Shravan KY, Madhusudan RY. Development of bilayered mucoadhesive patches for buccal delivery of felodipine: In vitro and ex vivo characterization. Curr Trends Biotech Pharm 2010;4:673-83

73. Cui Z, Mumper RJ. Bilayer films for mucosal (genetic) immunization via the Buccal route in rabbits. Pharm Res 2002;19:947-53.

74. Yang TZ, Wang XT, Yan XY, Zhang Q. Phospholipid deformable vesicles for buccal delivery of insulin. Chem Pharm Bull 2002;50:749-53.

75. Thimmasetty J, Pandey GS, Satheshbabu PR. Design and in vivo evaluation of carvedilol buccal mucoadhesive patches. Pak J Pharm Sci 2008;21:241-8.

76. Nair AB, Kumria R, Harsha S, Attimarad M, Al-Dhubiab BE, Alhaider IA. In vitro techniques to evaluate buccal films. J Control Release 2013;166:10-21.

77. Khanna R, Agarwal S, Ahuja A. Preparation and evaluation of bioerodible buccal tablets containing clotrimazole. Int J Pharm 1996;138:67-73.

78. Reddy MS, Mounika N. Formulation development and evaluation of buccal drug delivery of dapoxetine hydrochloride. Int J Pharm Sci Res 2020;11:3725-33.

79. Semalty M, Semalty A, Kumar G. Formulation and characterization of mucoadhesive buccal films glipizide. Ind J Pharm Sci 2008;70:43-8.

80. Guo JH. Investigating the surface properties and bioadhesion of buccal patches. J Pharm Pharmacol 1994;46:647-50.

81. Preis M, Woertz C, Kleinebudde P, Breitkreutz J. Oromucosal film preparations: Classification and characterization methods. Expert Opin Drug Deliv 2013;10:1303-17.

82. Morales JO, McConville JT. Manufacture and characterization of mucoadhesive buccal films. Eur J Pharm Biopharm 2011;77:187-99.

83. Chinna RP, Chaitanya KS, Madhusudan RY. A review on bioadhesive buccal drug delivery systems: Current status of formulation and evaluation methods. Daru 2011;19:385-403.

84. PR Newswire. Buccal Drug Delivery Systems: Opportunities and Challenges in Buccal, Sublingual Films, Tablets and Sprays-Detailed Analysis on Technologies and Pipeline Development. Vol. 25. New York: PR Newswire; 2015. p. 3429612.

85. Satishbabu B, Srinivasan B. Preparation and evaluation of buccoadhesive films of atenolol. Ind J Pharm Sci 2008;62:447-51.

86. Lueßen HL. Mucoadhesive polymers in peroral peptide drug delivery. I. Influence of mucoadhesive excipients on the proteolytic activity of intestinal enzymes. Eur J Pharm Sci 1996;4:117-28.

87. Khurana R, Ahuja A, Khar R. Development and evaluation of mucoadhesive films of miconazole nitrate. Indian $\mathrm{J}$ Pharm Sci 2000;62:447-51.

88. Adhikari SN, Nayak BS, Nayak AK, Mohanty B. Formulation and evaluation of buccal patches for delivery of atenolol. AAPS Pharm Sci Tech 2010;11:1038-44.

89. Chalamaiah M, Sharma PK. Pre-formulation and formulation approaches for buccal films. J Bioequivalence Availab 2016;8:246-8. 
90. Sudhakar Y, Kuotsu K, Bandyopadhyay AK. Buccal bioadhesive drug delivery-a promising option for orally less efficient drugs. J Control Release 2006;114:15-40.

91. Singh S, Jain S, Muthu MS, Tiwari S, Tilak R. Preparation and evaluation of buccal bioadhesive films containing clotrimazole. AASP Pharm Sci Tech 2008;9:660-7.

92. Betz G, Burgin PJ, Leuenberger H. Power consumption profile analysis and tensile strength measurements during moist agglomeration. Int $\mathrm{J}$ Pharm 2003;252:11-25.

93. Chun M K, Kwak B T, Choi H K. Preparation of buccal patch composed of cabopol, poloxomer and hydroxypropyl methylcellulose. Arch Pharm Res 2003;26:973-8.

94. USP, 23/NF 18, USP Convection, Rockville; 1996. p. 1792-5.

95. Nakamura F, Ohta $\mathrm{R}$, Machida $\mathrm{Y}$, Nagai $\mathrm{T}$. In vitro and in vivo nasal mucoadhesion of some water soluble polymers. Int J Pharm 1996; $134: 173-81$.
96. Parodi B, Russo E, Caviglioli G, Cafaggi S, Bignardi G. Development and characterization of a buccoadhesive dosage form of oxycodone hydrochloride. Drug Dev Ind Pharm 1996;22:445-50.

97. Palem CR, Gannu R, Doodipala N, Yamsani VV, Yamsani MR. Transmucosal delivery of domperidone from bilayered buccal patches: In vitro, ex vivo characterization. Arch Pharm Res 2011;34: 1701-10.

98. Ibrahim HM, Ahmed TA, Lila AE, Samy AM, Kaseem AA, Nutan MT. Mucoadhesive controlled release microcapsules of indomethacin: Optimization and stability study. J Microencapsul 2010;27:377-86.

99. Semalty A, Bhojwani M, Bhatt GK, Gupta GD, Shrivastav AK. Design and evaluation of mucoadhesive buccal films of diltiazem hydrochloride. Indian J Pharm Sci 2005;67:548-52.

100. Nappinnai M, Chnadanbala R, Balaijirajan R. Formulation and evaluation of nitrendipine buccak films. Indian J Pharm Sci 2008;70:631-5. 